\title{
On the pathogenesis of gastroesophageal reflux: The concept of gastroesophageal dyssynergia
}

\author{
Ahmed Shafik, MD, PhD, ${ }^{\text {a }}$ Ismail Shafik, MD, MCh, ${ }^{\text {a }}$ Olfat El-Sibai, MD, PhD, ${ }^{\mathrm{b}}$ and Ali A. Shafik, MD, MCh ${ }^{\mathrm{a}}$
}

From the Department of Surgery and Experimental Research, ${ }^{\text {a }}$ Faculty of Medicine, Cairo University, Cairo; and the Depart-

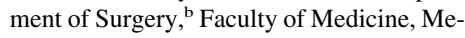
noufia University, Shebin El-Kom, Egypt.

Received for publication April 18, 2004; revisions received June 28, 2004; accepted for publication Aug 20, 2004.

Address for reprints: Ahmed Shafik, MD, $\mathrm{PhD}, 2$ Talaat Harb St, Cairo, 11121, Egypt (E-mail: shafik@ahmed-shafik.org).

J Thorac Cardiovasc Surg 2005;130:401-7

$0022-5223 / \$ 30.00$

Copyright $\odot 2005$ by The American Association for Thoracic Surgery

doi:10.1016/j.jtcvs.2004.08.048
Objectives: The cause of lower esophageal sphincter incompetence in gastroesophageal reflux disease is not clearly understood. We investigated the hypothesis that the esophagogastric junction incompetence results from failure of the gastric distention to produce the lower esophageal sphincter and crural diaphragm contraction caused by a disordered reflex action.

Methods: The study was performed in 19 subjects (mean age, $42.6 \pm 7.2$ years; 11 men and 8 women) who had reflux esophagitis and hiatus hernia and were scheduled for a fundoplication operation. Eight control volunteers (mean age, $41.8 \pm 6.9 ; 5$ men and 3 women) who had huge supraumbilical ventral hernia but no reflux esophagitis or hiatus hernia were studied during operative hernia repair. The electromyographic activity and pressure response of the lower esophageal sphincter and crural diaphragm to separate esophageal and gastric distention were recorded.

Results: In the control subjects (volunteers) esophageal distention caused diminished electromyographic activity of the crural diaphragm and lower esophageal sphincter with decreased esophagogastric junction pressure, whereas gastric distention increased the electromyographic activity of the crural diaphragm and lower esophageal sphincter with increased esophagogastric junction pressure. In the patients the crural diaphragm and lower esophageal sphincter showed diminished resting electromyographic activity, with either no response or a paradoxical response to esophageal or gastric distention.

Conclusion: The current study has demonstrated that the lower esophageal sphincter and crural diaphragm in patients with gastroesophageal reflux disease exhibited a diminished resting electric activity and either did not respond or reacted paradoxically to esophageal and gastric distention, constituting what we call esophagosphincteric and gastroesophageal paradox or dyssynergia. The cause of lower esophageal sphincter and crural diaphragm dysfunction is not known; a neurogenic cause was proposed. Further studies are required to investigate this point.

$\mathrm{D}$ espite extensive studies on the lower esophageal sphincter (LES) incompetence seen in patients with gastroesophageal reflux disease (GERD), the cause of this incompetence is not clearly understood. ${ }^{1,2}$ Many theories have been advanced, but none have proved entirely satisfactory. One theory was put forward discussing whether the reduced esophagogastric junction (EGJ) pressure is a primary phenomenon or the result of chronic esophagitis and epithelial damage. Eastwood and colleagues ${ }^{3}$ proved that the induction of esophagitis in cats reduced the basal EGJ pressure. On the other hand, other investigators, including Timmer and associates, ${ }^{4}$ showed that healing of esophagitis in human subjects did not improve the reduced EGJ pressure. 
A more recent hypothesis for the EGJ incompetence was adopted by Korn and coworkers. ${ }^{1}$ They reported that the dilatation of the EGJ and cardia is tantamount to an irreversible change in the arrangement of the muscle bands that shape the LES, and consequently, its function is compromised. However, the cause of these anatomic changes has not been considered.

In GERD the peristaltic activity of the esophageal body is lost or impaired during reflux episodes. ${ }^{5,6}$ There has been a controversy about whether the esophageal body dysmotility is a primary phenomenon like dysmotility of the LES or a secondary phenomenon in response to esophageal acid exposure.

Previous studies have shown that the pressure at the lower esophagus is under the control of reflex actions that act on the $\operatorname{LES}^{7,8}$ and the crural diaphragm (CD). ${ }^{9}$ The lower esophagus is presumably surrounded by 2 sphincters, the LES and the CD, which proved to have a sphincteric action. ${ }^{9}$ The LES and CD relax on esophageal distention, an action that appears to be mediated through the esophagosphincter inhibitory ${ }^{7}$ and esophagocrural ${ }^{9}$ reflexes, respectively. Meanwhile, they contract on gastric distention caused by the gastroesophageal $^{8}$ and gastrocrural ${ }^{9}$ reflexes. LES and CD relaxation allow the food bolus to pass to the stomach, whereas their contraction prevents gastroesophageal reflux.

In the current study we investigated the hypothesis that EGJ incompetence results from failure of the gastric distention to produce the LES and CD contraction caused by a disordered reflex action.

\section{Material and Methods \\ Subjects}

The study comprised 19 subjects ( 11 men and 8 women; mean \pm SD age, $42.6 \pm 7.2$ years; range, $38-48$ years) who had reflux esophagitis associated with hiatus hernia of a mean duration of $9.6 \pm 2.8$ years (range, 7-13 years). They were scheduled for operative repair after long-term medical treatment. The study was carried out during a fundoplication operation. The patients provided informed consent after having been fully informed about the nature of the study, the tests to be done, and their role in the study.

The study also included 8 control subjects (5 men and 3 women; mean $\pm \mathrm{SD}$ age, $41.8 \pm 6.9$ years; range, $36-47$ years) with no reflux esophagitis or hiatus hernia. They had huge supraumbilical ventral hernia. The study was performed during the hernia repair.

Physical examination of both the study patients and the control subjects resulted in normal findings. The results of laboratory work comprising blood count, renal and hepatic function tests, and electrocardiography were unremarkable. The study was approved by the Cairo University Faculty of Medicine Review Board and Ethics Committee.

\section{Methods}

The tests were performed after achievement of general anesthesia, which was induced with thiopentone sodium $(5-10 \mathrm{mg} / \mathrm{kg})$, succinylcholine (INN: suxamethonium; $1 \mathrm{mg} / \mathrm{kg}$ ), and endotracheal intubation and was maintained with $50 \%$ nitrous oxide and $1 \%$ to $2 \%$ isoflurane. After the succinylcholine action had ceased and spontaneous respiration had returned, the tests were performed. After the end of testing, atracurium $(0.4-0.5 \mathrm{mg} / \mathrm{kg}$ ) was administered, and controlled respiration was started. During general anesthesia, a $6 \mathrm{~F}$ polyethylene tube with an empty polyethylene balloon of $1.5 \mathrm{~cm}$ in diameter tied to its distal end was introduced into the stomach. A second similar $6 \mathrm{~F}$ tube tipped with a $0.5-\mathrm{cm}$-diameter balloon was introduced into the esophagus to lie within the LES. Each tube had a metal ring applied to its distal end for fluoroscopic control and was connected to a strain gauge pressure transducer (Statham 230 B, Oxnard, Calif).

\section{Electromyographic Activity of the CD and LES}

Although the abdomen was being opened through a midline abdominal incision, a concentric electromyographic (EMG) needle electrode measuring $40 \mathrm{~mm}$ in length and $0.65 \mathrm{~mm}$ in diameter (Type 13L49; Disa, Copenhagen, Denmark) was introduced into the $\mathrm{CD}$ in the area surrounding the esophagus. A ground electrode was applied to the thigh. A standard EMG apparatus (Type MES; Medelec, Woking, United Kingdom) was used to amplify and display the recorded potentials. Films of the potentials were taken on light-sensitive paper (Linagraph type 1895; Kodak, Rochester, $\mathrm{NY}$ ) to measure the duration of the motor unit action potentials (MUAPs). The EMG signals were also stored on an FM tape recorder (type 7758A; Hewlett-Packard, Waltham, Mass) for further analysis as required.

In the control subjects we tested the normality of the CD EMG activity before the experiments were started. This was done by means of CD stimulation with a needle electrode introduced into the $\mathrm{CD}$ and by means of registration of the MUAPs from the already inserted needle electrode. The CDs of all the control subjects had normal EMG activities.

Another similar needle electrode was introduced into the LES at the area of the esophageal high-pressure zone, as determined in the manometric studies. The waves were recorded on a standard EMG apparatus, as mentioned previously.

\section{Manometric Studies}

A manometric $6 \mathrm{~F}$ catheter was introduced into the esophagus so that its distal end lay in the high pressure zone at the lower end of the esophagus, as determined by using the pull-though technique. The catheter had 2 side ports and a metal clip applied to its distal closed end for fluoroscopic control. The catheter was connected to a pneumohydraulic infusion system (Arndorfer Medical Specialities, Greendale, Wis), with a pump delivering saline solution continuously through the capillary tube at a rate of $0.6 \mathrm{~mL} / \mathrm{min}$. The transducer outputs were registered on a rectilinear recorder (model RS-3400; Gould Inc, Cleveland, Ohio). Occlusion of the recording orifice produced a pressure increase rate that was greater than $250 \mathrm{~cm} \mathrm{H}_{2} \mathrm{O}$ per second. During pressure measurements, the catheter was rotated so as to record anteroposterior and lateral pressures. 


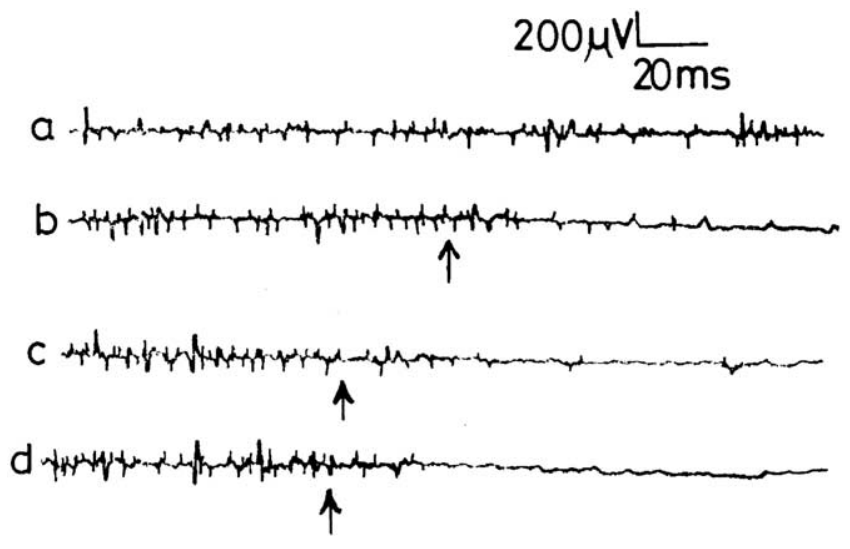

Figure 1. EMG activity of the CD of a control subject undergoing esophageal balloon distention with normal saline in increments of $2 \mathrm{~mL}$ : a, basal activity; b, 2-mL distention; c, 6- $\mathrm{mL}$ distention; and $\mathrm{d}, \mathbf{1 0}-\mathrm{mL}$ distention. $\uparrow$, Distention.

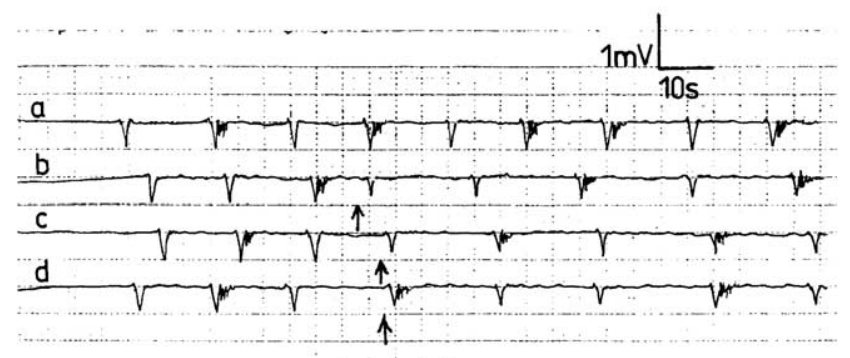

Figure 2. EMG activity of the LES of a control subject undergoing esophageal balloon distention with normal saline in increments of $2 \mathrm{~mL}$ : a, basal activity; b, 2- $\mathrm{mL}$ distention; c, 6- $\mathrm{mL}$ distention; and $\mathbf{d}, 10-\mathrm{mL}$ distention. $\uparrow$, Distention.

\section{Esophageal and Gastric Balloon Distention}

The esophageal balloon was filled with normal saline up to $10 \mathrm{~mL}$ in increments of $2 \mathrm{~mL}$, and the EMG response of the CD and LES, as well as the EGJ pressure response to upper-, middle-, and lower-third esophageal distention, were recorded. The latency of the response was measured from the start of stimulation (distention) to the first deflection of the muscle action potential complex.

The gastric balloon was filled with normal saline in increments of $10 \mathrm{~mL}$ and up to $100 \mathrm{~mL}$, and the EMG response of the CD and LES, as well as the EGJ pressure response to gastric distention, were registered.

The recordings were repeated at least twice in the individual subject to ensure reproducibility, and the mean value was calculated. The results were analyzed statistically with the Student $t$ test, and values were presented as means \pm SD.

\section{Results}

The tests were completed in all the subjects, with no adverse side effects.

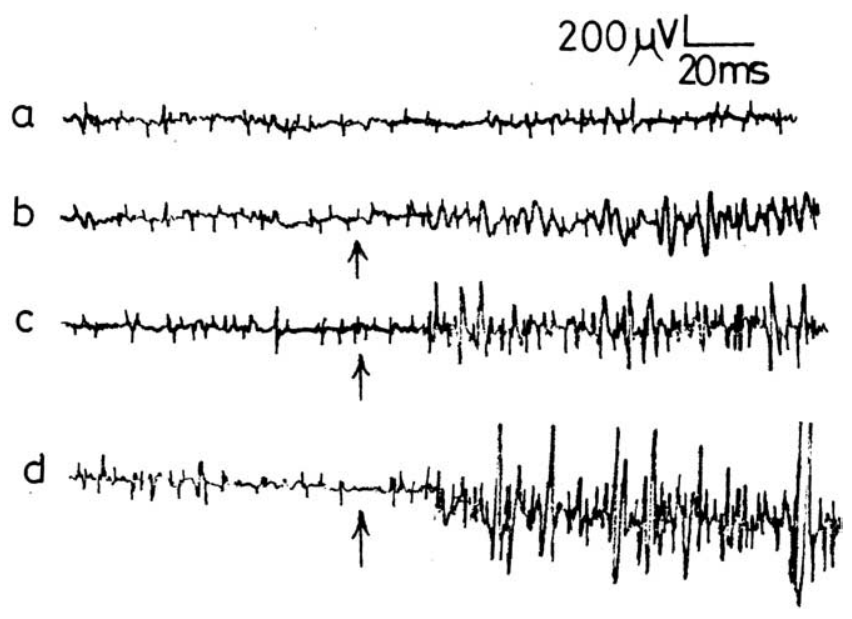

Figure 3. EMG activity of the CD of a control subject undergoing gastric balloon distention in increments of $10 \mathrm{~mL}$ of normal saline: a, basal activity; b, 30-mL distention; c, $60-\mathrm{mL}$ distention; and $\mathrm{d}$, 100-mL distention. $\uparrow$, Distention.

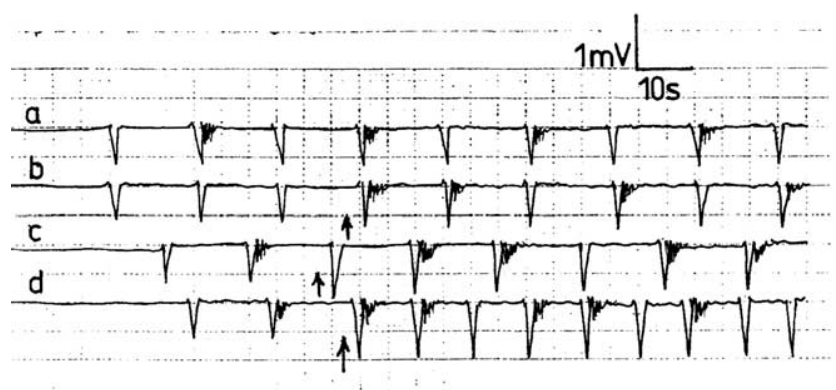

Figure 4. EMG activity of the LES of a healthy control subject undergoing gastric balloon distention in increments of $10 \mathrm{~mL}$ : $a$, basal activity; b, 30-mL distention; c, $60-\mathrm{mL}$ distention; and $\mathrm{d}$, 100-mL distention. $\uparrow$, Distention.

\section{Control Subjects}

The CD showed a mean basal EMG activity of $118.7 \pm 18.4$ $\mu \mathrm{V}$ (range, 92-138 $\mu \mathrm{V}$; Figure 1). Distention of the middle third of the esophagus with $2 \mathrm{~mL}$ of saline reduced the MUAPs of the CD to a mean of $14.6 \pm 4.4 \mu \mathrm{V}$ (range, $6-26$ $\mu \mathrm{V} ; P<.001$; Figure 1). This MUAP decrease was maintained during esophageal distention and returned to the basal value on balloon emptying.

Repeated successive esophageal distention produced similar CD responses, with no significant difference $(P>$ $.05)$. Esophageal balloon distention with 4, 6, 8, and $10 \mathrm{~mL}$ of normal saline caused the same CD response as the distention with $2 \mathrm{~mL}(P>.05$, Figure 1). The latency recorded a mean of $19.6 \pm 2.5 \mathrm{~ms}$ (range, $15-23 \mathrm{~ms}$ ).

The LES exhibited electric activity in the form of slow waves (SWs) and fast activity spikes or action potentials 


\section{$200 \mu \mathrm{VL} \frac{\mathrm{L}}{20 \mathrm{~ms}}$}
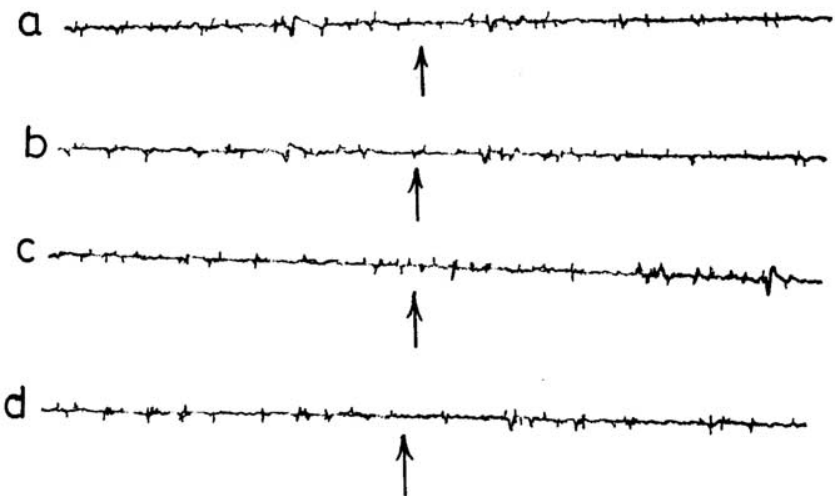

Figure 5. EMG activity of the CD of a patient with gastroesophageal reflux undergoing esophageal balloon distention with normal saline in increments of $2 \mathrm{~mL}$ : a, basal activity; b, 2-mL distention; c, 6-mL distention; and d, 10-mL distention. It shows no significant change. $\uparrow$, Distention.

(Figure 2). The SWs were monophasic, with negative deflection; they had a constant frequency, amplitude, and conduction velocity in the individual subject, whereas the action potentials occurred randomly, were inconsistent, and followed or were superimposed over the SWs (Figure 2). Middle-third esophageal balloon distention with $2 \mathrm{~mL}$ of saline produced a significant decrease in the LES EMG activity (Figure 2). The LES electric activity returned to the predistention state on esophageal deflation. The esophageal response was reproducible by means of successive repeti-

Table I. Pressure within the esophagogastric junction during gastric distention with a balloon filled with normal saline in increments of 10 and up to $100 \mathrm{~mL}^{*}$

\begin{tabular}{lcc}
\hline $\begin{array}{l}\text { Pressure }\left(\mathbf{c m ~ H}_{\mathbf{2}} \mathbf{0}\right) \\
\text { Saline }\end{array}$ & Mean \\
\hline $\begin{array}{l}\text { In balloon }(\mathrm{mL}) \\
\text { Basal }\end{array}$ & \\
10 & $24.3 \pm 5.8$ & $17-32$ \\
20 & $24.2 \pm 5.8 \dagger$ & $17-32$ \\
30 & $23.7 \pm 5.5 \dagger$ & $16-30$ \\
40 & $36.8 \pm 7.2 \ddagger$ & $28-48$ \\
50 & $40.2 \pm 6.7 \ddagger$ & $36-56$ \\
60 & $49.6 \pm 7.1 \ddagger$ & $42-63$ \\
70 & $58.8 \pm 6.6 \S$ & $50-69$ \\
80 & $67.2 \pm 6.2 \S$ & $61-78$ \\
90 & $75.5 \pm 7.3 \S$ & $68-83$ \\
100 & $81.4 \pm 6.3 \|$ & $76-88$ \\
\hline$P$ & $90.6 \pm 7.3 \|$ & $84-104$ \\
\hline
\end{tabular}

$P$ values were compared with basal values. $*$ Values are presented as means \pm SD. $\dagger P>.05 . \ddagger P<.05 . \S P<.01 . \| P<.001$.

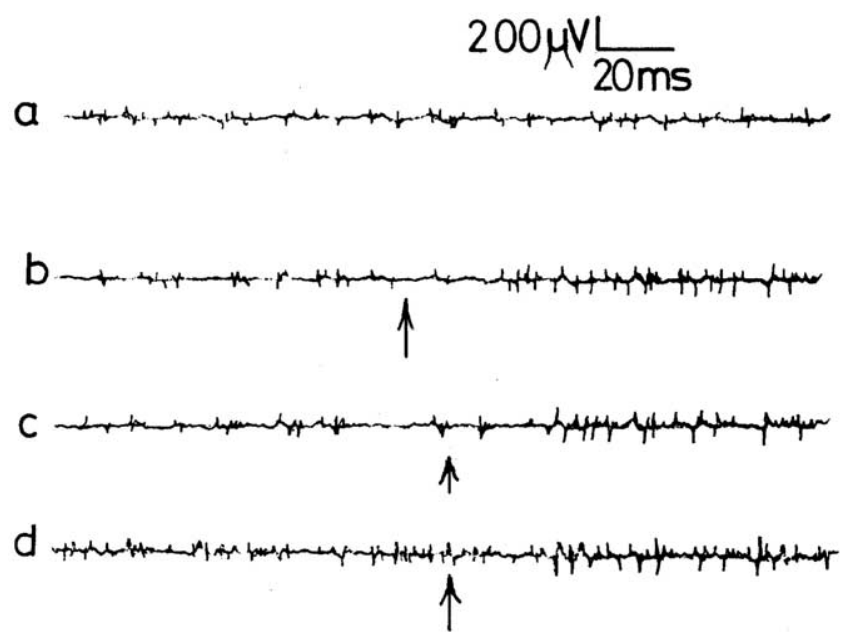

Figure 6. EMG activity of the CD of a patient with gastroesophageal reflux undergoing esophageal balloon distention with normal saline in increments of $2 \mathrm{~mL}$ : a, basal activity; b, 2-mL distention; c, 6-mL distention; and d, 10-mL distention. It showed increased activity. $\uparrow$, Distention.

tion of esophageal balloon distention and emptying. Four-, 6-, 8-, and 10-mL distention produced an LES response similar to the 2-mL distention, with no significant difference $(P>.05)$. The mean latency was $21.7 \pm 1.9 \mathrm{~ms}$ (range, 14-25 ms).

EMG activity of the CD on gastric balloon distention in increments of $10 \mathrm{~mL}$ of normal saline and up to $100 \mathrm{~mL}$ is displayed in Figure 3. Ten- and $20-\mathrm{mL}$ gastric balloon fillings produced insignificant changes in the CD EMG activity $(P>.05)$, whereas distention with 30 to $100 \mathrm{~mL}$ progressively increased the CD EMG activity (Figure 3). The CD EMG response to gastric balloon distention lasted as long as gastric distention was maintained. On gastric balloon emptying, the CD EMG activity returned to the predistention values, with no significant difference. Repeated successive gastric distention with different balloon volumes (up to $100 \mathrm{~mL}$ ) evoked the CD EMG response without fatigue. The mean latency was $19.2 \pm 4.3 \mathrm{~ms}$ (range, 13-25 ms).

Gastric balloon distention with 10 and $20 \mathrm{~mL}$ of normal saline produced no significant changes in the LES EMG activity (Figure 4), whereas 30- to $60-\mathrm{mL}$ distention caused a progressive increase in the LES EMG activity (Figure 4). The LES response was sustained as long as esophageal distention was maintained. On balloon emptying, the LES EMG activity returned to the predistention values. Repeated successive gastric distention with different volumes (up to $100 \mathrm{~mL}$ ) evoked the LES response without fatigue.

The basal EGJ pressure recorded a mean of $24.3 \pm 5.8$ $\mathrm{cm} \mathrm{H}_{2} \mathrm{O}$ (range, 17-32 $\mathrm{cm} \mathrm{H}_{2} \mathrm{O}$ ). On esophageal balloon 


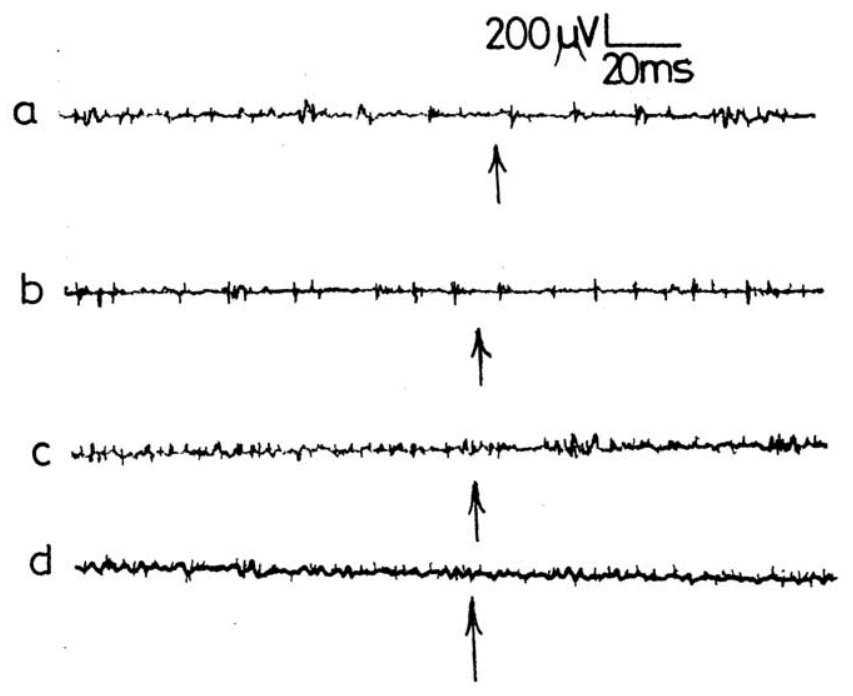

Figure 7. EMG activity of the CD of a patient with gastroesophageal reflux undergoing gastric balloon distention in increments of $10 \mathrm{~mL}$ of normal saline: a, basal activity; $b, 30-\mathrm{mL}$ distention; $c$, 60-mL distention; and d, 100-mL distention. It showed no significant change. $\uparrow$, Distention.

\section{$200 \mu \mathrm{VL} 20 \mathrm{~ms}$}

a

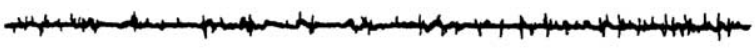

b

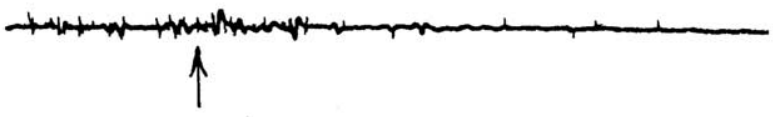

C

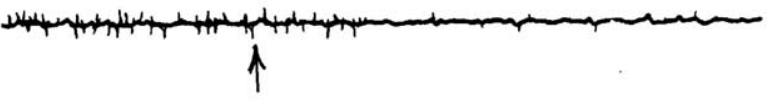

d

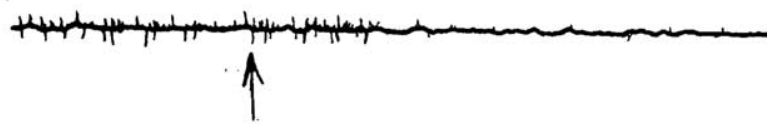

Figure 8. EMG activity of the CD of a patient with gastroesophageal reflux undergoing gastric balloon distention in increments of $10 \mathrm{~mL}$ of normal saline: a, basal activity; $b, 30-\mathrm{mL}$ distention; $c$, 60-mL distention; and d, 100-mL distention. It showed diminished activity. $\uparrow$, Distention.

distention with $2 \mathrm{~mL}$ of normal saline, the pressure within the EGJ decreased to a mean of $6.2 \pm 1.2 \mathrm{~cm} \mathrm{H}_{2} \mathrm{O}$ (range, $\left.4-8 \mathrm{~cm} \mathrm{H}_{2} \mathrm{O} ; P<.001\right)$. Larger fillings of the esophageal balloon with up to $10 \mathrm{~mL}$ produced an EGJ pressure response similar to the 2-mL balloon distention $(P>.05)$. The EGJ pressure response to esophageal distention was

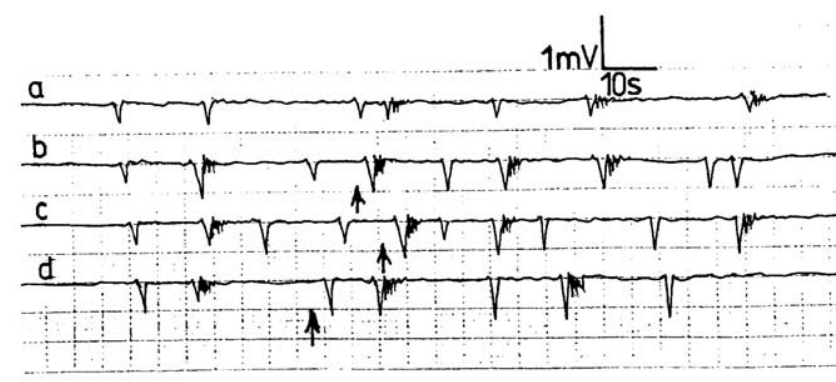

Figure 9. EMG activity of the LES of a patient with gastroesophageal reflux undergoing esophageal balloon distention with normal saline in increments of $2 \mathrm{~mL}$ : a, basal activity; b, 2-mL distention; c, 6-mL distention; and d, 10-mL distention. It showed increased activity. $\uparrow$, Distention.

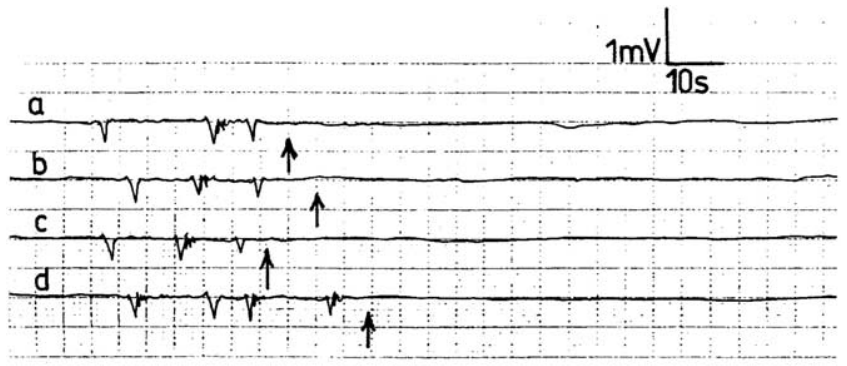

Figure 10. EMG activity of the LES of a patient with gastroesophageal reflux undergoing esophageal balloon distention with normal saline in increments of $2 \mathrm{~mL}$ : a, basal activity; b, 2-mL distention; c, 6-mL distention; and d, 10-mL distention. It showed no activity. $\uparrow$, Distention.

maintained throughout esophageal distention. On esophageal balloon deflation, the EGJ pressure returned to the predistention values. The EGJ pressure decrease with esophageal balloon distention was less in the elderly subjects than in the young subjects and less in women than in men; the difference was, however, statistically insignificant $(P>.05)$. Furthermore, repeated successive esophageal distention with the aforementioned different balloon volumes evoked the EGJ response without fatigue. The same results were obtained when the saline-filled balloon was moved to the different sections of the esophagus.

The mean basal gastric pressure was $5.7 \pm 1.5 \mathrm{~cm} \mathrm{H}_{2} \mathrm{O}$ (range, $4-8 \mathrm{~cm} \mathrm{H}_{2} \mathrm{O}$ ). The pressure response within the EGJ to gastric balloon distention in increments of $10 \mathrm{~mL}$ up to $100 \mathrm{~mL}$ of normal saline is exhibited in Table 1. Gastric distention with 10- and 20-mL balloon fillings caused no significant EGJ pressure changes $(P>.05)$, whereas distention with 30 to $100 \mathrm{~mL}$ produced a significant increase (Table 1). The EGJ pressure response was maintained as long as gastric distention was sustained. On gastric balloon 
emptying, the EGJ pressure returned to the predistention values. Repeated successive gastric distention with the different balloon volumes evoked the EGJ response without fatigue.

\section{Patients With Gastroesophageal Reflux}

Compared with the control subjects, the CD showed a diminished mean basal EMG activity of $56.7 \pm 10.5 \mu \mathrm{V}$ (range, 42-76 $\mu \mathrm{V}$; Figure 5). Balloon distention of the middle third of the esophagus with 2 and up to $10 \mathrm{~mL}$ of normal saline caused no significant changes in the CD EMG activity in 8 patients (Figure 5) and increased activity in 11 patients (Figure 6); the increased activity showed no significant difference between the 2- and $10-\mathrm{mL}$ esophageal distention. When the balloon was moved to the different sections of the esophagus and filled with the abovementioned volumes, we obtained similar results to that of the middlethird esophageal distention. These results were achieved in all the studied subjects and were reproducible.

The EMG activity of the CD on gastric balloon distention up to $100 \mathrm{~mL}$ of normal saline showed no significant changes from the resting activity in 7 patients $(P>.05$, Figure 7). In the remaining 12 patients, the CD EMG activity was diminished (Figure 8). The recordings were reproducible, with no significant difference when they were repeated in the same subject.

The LES showed diminished or no resting electric activity compared with that seen in the control subjects (Figure 9). On 2- to $10-\mathrm{mL}$ esophageal balloon distention, it recorded increased electric activity in 11 patients (Figure 9) and no activity in 8 patients (Figure 10).

The mean basal pressure within the EGJ was $6.6 \pm 1.3$ $\mathrm{cm} \mathrm{H}_{2} \mathrm{O}$ (range, 5-9 $\mathrm{cm} \mathrm{H}_{2} \mathrm{O} ; P<.01$ ). Esophageal balloon distention with $2 \mathrm{~mL}$ and up to $10 \mathrm{~mL}$ of normal saline produced no significant EGJ pressure changes $(P>.05)$ in 8 patients. In 11 patients the EGJ pressure showed a significant increase to a mean of $16.6 \pm 2.4 \mathrm{~cm} \mathrm{H}_{2} \mathrm{O}$ (range, 14-20 $\mathrm{cm} \mathrm{H}_{2} \mathrm{O}$ ). The gastric pressure recorded a mean of $6.3 \pm 1.2 \mathrm{~cm} \mathrm{H}_{2} \mathrm{O}$ (range, 5-8 $\mathrm{cm} \mathrm{H}_{2} \mathrm{O}$ ). Gastric balloon distention in increments of $10 \mathrm{~mL}$ up to $100 \mathrm{~mL}$ of normal saline exhibited insignificant changes in the EGJ pressure in 8 patients and diminished pressure to a mean of $2.4 \pm 0.4$ cm $\mathrm{H}_{2} \mathrm{O}$ (range, $1-3 \mathrm{~cm} \mathrm{H}_{2} \mathrm{O} ; P<.05$ ) in 11 patients.

\section{Discussion}

The initiative factors for GERD are still unknown. ${ }^{1,2,10}$ The treatment presumably controls the disease through the management of perpetrating or exacerbating factors. ${ }^{10}$ The current study might shed some light on the pathogenesis of GERD.

Our investigations have revealed that the EMG activity of the LES and CD in the control subjects decreased on esophageal distention and increased on gastric distention; this would denote that the CD and LES relax or contract on esophageal and gastric distention, respectively. We recently demonstrated that $\mathrm{CD}$ relaxation on esophageal distention is mediated through the esophagocrural inhibitory reflex and $\mathrm{CD}$ contraction on gastric distention through the gastrocrural excitatory reflex. ${ }^{9}$ The EGJ pressure responded to esophageal and gastric distention by means of a respective decrease or increase, and these actions were shown, in a recent study, to be mediated through the esophagosphincteric ${ }^{7}$ and gastroesophageal ${ }^{8}$ reflexes.

The current study suggests that the lower esophagus is surrounded by 2 sphincters, the LES and the CD, which respond to esophageal and gastric balloon distention. The LES is a smooth muscle sphincter, and the CD is a striated sphincter. ${ }^{11-13}$ The response of the CD and LES to esophageal and gastric distentions though relaxation and contraction, respectively, suggests that they have a sphincteric action. The gastroesophageal competence presumably depends, under normal physiologic conditions, on the sphincteric action of the LES and CD, which encircle the lower esophagus. The response of these 2 sphincters to gastric distention is reflex ${ }^{8,9}$ and is suggested to be the principal factor in the gastroesophageal competent mechanism. Preceding studies have shown that the LES and CD respond to gastric distention by increasing their EMG activity through reflex mechanisms mediated by the gastroesophageal and gastrocrural reflexes, respectively.,

\section{Gastroesophageal Dyssynergia}

The resting EGJ pressure was significantly lower in patients with GERD than in the control subjects. This seems to be due to a dysfunction of the LES and CD, as evidenced by their diminished resting EMG activity. Furthermore, in addition to the presumably patent lower esophagus resulting from the diminished LES and CD EMG activity, the 2 sphincters reacted to gastric distention differently in the patients than in the control subjects. They either did not respond or reacted paradoxically by relaxation. The gastroesophageal reflux in these cases is apparently the result of not only the patent lower esophagus but also the nonresponse or relaxation of these sphincters on gastric distention. Thus a state of gastroesophageal paradox or dyssynergia seems to prevail in gastroesophageal reflux. Failure of the LES to relax or its increased (paradoxical) activity on esophageal distention constitute esophagosphincteric paradox or dyssynergia. Some of the patients with GERD might complain of dysphagia, ${ }^{14,15}$ which could be due to esophagosphincteric paradox or dyssynergia or to other factors, including esophagitis, and later on stricture formation. However, dysphagia in GERD is not a common complaint because although the LES relaxation on esophageal distention might be absent, the LES is already relaxed, and the lower esophagus is thus supposedly patent. 
In our current work we could demonstrate the presence of esophagosphincteric and gastroesophageal paradox or dyssynergia in patients with GERD. The cause of this paradox or dyssynergia needs to be discussed.

\section{Pathogenesis of GERD: A Novel Concept}

There is a long-standing debate regarding the pathogenesis of GERD and the roles of hiatus hernia and the LES in the development of gastroesophageal reflux. ${ }^{10}$ Some investigators believe that hiatus hernia is the major cause of GERD. ${ }^{10}$ Their opinion that the antireflux barrier is congenitally underdeveloped derived support from the fact that in many adults hiatus hernia could be traced back to their childhood. ${ }^{10,16,17}$ Another theory proposed that the antireflux barrier in children and adults is gradually weakened as a result of years of straining at defecation or from other causes. ${ }^{10}$ Other investigators postulated a hypothesis on the basis of the progressive anatomic dilatation of the gastroesophageal junction or cardia. ${ }^{1,18,19}$ The dilatation of the cardia produces an irreversible change in the arrangement of the muscular bands that shape the LES and results in a mechanically defective sphincter. The authors agree that this is just a hypothesis. However, none of these hypotheses proved entirely satisfactory.

As already mentioned, the response of the LES and CD to esophageal or gastric distention is reflex and mediated through esophagosphincteric and esophagocrural reflexes and gastroesophageal and gastrocrural reflexes. ${ }^{7-9}$ The reflex arc comprises an ascending limb that includes the esophagus or stomach and a descending limb that includes the LES or CD. The current results seem to point to a dysfunction of the reflex arc, which presumably involves the descending limb represented by the LES and CD. This is evidenced by the diminished or absent resting EMG activity of the LES and CD, as well as the absent or paradoxical response of these 2 sphincters on esophageal or gastric distention. However, we could not, in our current investigation, develop a proposal as to the cause behind the weakening of LES and CD; this point requires further study.

In conclusion, the current study has demonstrated that the LES and CD in patients with GERD exhibited a diminished resting electric activity and either did not respond or reacted paradoxically to esophageal and gastric distention, constituting what we call esophagosphincteric and gastroesophageal paradox or dyssynergia. The cause of the LES and $\mathrm{CD}$ dysfunction is not known. It remains to be seen from further investigations whether a neurogenic cause could be the causative factor of this phenomenon.

Margot Yehia assisted in preparation of the manuscript.

\section{References}

1. Korn O, Csendes A, Burdiles P, Braghetto I, Stein HJ. Anatomic dilatation of the cardia and competence of the lower esophageal sphincter: a clinical and experimental study. J Gastrointest Surg. 2000;4:398-406.

2. Kauer WK, Peters JH, DeMeester TR, Feussner H, Ireland AP, Stein $\mathrm{HJ}$, et al. Composition and concentration of bile acid reflux into the esophagus of patients with gastroesophageal reflux disease. Surgery. 1997;122:874-81.

3. Eastwood GL, Castell DO, Higgs RH. Experimental esophagitis in cats impairs lower esophageal sphincter pressure. Gastroenterology. 1975; 69:146-53.

4. Timmer R, Breumelhaf R, Nadorp JHSM, Smout AJPM. Esophageal motility and gastroesophageal reflux before and after healing of reflux esophagitis. Gut. 1994;35:1519-22.

5. Singh P, Taylor RH, Colin-Jones DG. Esophageal motor dysfunction and acid exposure in reflux esophagitis are more severe if Barrett's metaplasia is present. Am J Gastroenterol. 1994;89:349-56.

6. Buttar NS, Falk GW. Pathogenesis of gastroesophageal reflux and Barrett's esophagus. Mayo Clin Proc. 2001;76:226-34.

7. Shafik A. Esophago-sphincter inhibitory reflex. Role in deglutition mechanism and esophageal achalasia. J Invest Surg. 1996;9:37-44.

8. Shafik A. Recognition of gastro-esophageal reflex in dogs and its role in lower esophageal sphincter competence. Eur Surg Res. 1998;30: 352-8.

9. Shafik A, Shafik I, El-Sibai O, Mostafa RM. The effect of esophageal and gastric distension on the crural diaphragm with identification of the esophago-crural and gastro-crural reflexes. Hepato-Gastroenterology. In press.

10. Sontag SJ. The lower esophageal sphincter versus the hiatus hernia in the arena of gastroesophageal reflux disease. A revisited subject. In: Giuli R, Siewert JR, Couturier D, Scarpignato C, editors. Barrett's esophagus; the main etiologic factors. Vol. 1. Paris: John Libbey Eurotext; 2003. p. 7-11.

11. Patti MG, Gantert W, Way LW. Anatomy of esophagus and gastroesophageal junction. Surg Clin North Am. 1997;77:959-69.

12. Korn O, Stein HJ, Richter T, Liebermann-Meffert D. Gastroesophageal sphincter: a model. Dis Esophagus. 1997;10:105-9.

13. Mittal RK, Balaban DH. The esophagogastric junction. $N$ Engl J Med. 1997;336:924-32.

14. Werdmuller BFM, van der Putten ABMM, Loffeld RJLF. The presentation of reflux esophagitis, hiatus hernia, Barrett's esophagus, and "reflux-like" dyspepsia: a prospective clinical and endoscopic study. Dis Esophagus. 1996;9:285-9.

15. Triadafilopoulos G, Sharma PR. Features of symptomic gastroesophageal reflux disease in elderly patients. Am J Gastroenterol. 1997;92: 2007-11.

16. Astley R, Carre IJ, Langmeed-Smith R. A 20-year prospective follow-up of infantile hiatal hernia. Br J Radiol. 1976;50:400-3.

17. Johnson BT, Carre IJ, Thomas PS, Collins BJ. Twenty to 40 years follow-up of infantile hiatal hernia. Gut. 1995;36:809-12.

18. Skinner DB. Pathophysiology of gastroesophageal reflux. Ann Surg. 1985;202:546-56.

19. Stein HJ, DeMeester TR, Hinder RA. Outpatient physiologic testing and surgical management of foregut motility disorders. Curr Probl Surg. 1992;29:415-44. 